\title{
Identification and Prioritization of Flood Conditioning Factors using ISM and MICMAC Technique
}

\author{
Swati Sharma, Vineet Sharma
}

\begin{abstract}
Floods can be considered as one of the most devastating natural hazard in developing and developed countries around the world. Apart from physical damage and financial loss, floods results in tremendous loss of human lives. Current risk assessment methods are not efficacious due to lack of analysis of the flood causing factors. There are enormous factors causing flood. The paper aims to apply a structural modeling technique for flood conditioning factors identification and prioritization by establishing a relation among them. The paper presents a framework for various flood conditioning factors. The framework uses Interpretive Structural Modeling (ISM) for modeling. Further matrice d'impacts croises-multiplication appliequé à un classement (MICMAC) [17] method is applied to recognize both direct and indirect relationship between factors and access the most prioritized flood conditioning factor. Their relationship among the factors is established, which would help in effective risk mitigation management.
\end{abstract}

Index Terms: Flood Conditioning Factors, Interpretive Structural Modeling, MICMAC, Reach ability matrix, Structural Self Interaction Matrix component

\section{INTRODUCTION}

Flood disaster is regarded as the most frequent and destructive types of disasters around the world [7]. Worldwide researches indicate that continuously increasing floods is a threat to millions of the citizens residing in various countries, and thus will remain the most widely distributed natural hazard leading to tremendous economic and social loss.

Floods being natural hazard cannot be eliminated from the earth. Despite tremendous progress in technology while dealing with disasters, natural phenomena greatly affect the social and economic conditions of the entire world. It is almost impossible to fully regain the damage caused by natural disasters, but it is possible to minimize its effect and mitigate the risk by finding effective risk reduction methods [3].

This research paper gives a structure that helps in modeling and establishing certain relationships (direct and indirect) among the various flood conditioning factors. By

Revised Manuscript Received on July 10, 2019.

Swati Sharma, Computer Science and Engineering Department, KIET Group Of Institutions, Ghaziabad, India

Dr.Vineet Sharma, Computer Science and Engineering Department, KIET Group Of Institutions, Ghaziabad, India. analyzing these floods conditioning factors researchers can focus their efforts on most critical factors and thus flood mitigation strategies can be designed accordingly.

This paper uses Interpretive Structural Modeling (ISM) for modeling and measuring flood conditioning factors. "Interpretive Structural Modeling" (ISM) is an integrated framework that helps in identifying the structural model delineating relationships between various factors. In this research, flood conditioning factors are analyzed using ISM methodology thus showing interrelationships between them [14][13].

An extensive literature survey was done for identifying the various flood conditioning factors. Based on literature survey of the tremendous work done in the field the factors were identified and were used in identifying a relationship matrix, which is further used to develop an ISM model for flood conditioning factors.

MICMAC stands for Matrice d'Impacts Croise's Multiplication Appliquée a' un Classement, which means "cross impact matrix multiplication applied to classification"[26].

In MICMAC, analysis is done based on the dependence and driving power of the identified variables. It categorizes variables into four quadrants, named as autonomous, dependent, linkage and independent. First quadrant factors have weak driver power and also weak dependence power and are thus called autonomous factors. Factors having weak driver power but with a strong dependence power will fall in second quadrant and are called dependent factors. Factors having both strong driver and dependence power will fall in third quadrant and are called linkage elements. The driver or independent variables, having low dependence but high driving power will fall in quadrant number four [11].

The remaining paper is divided into different sections. The second section gives intensive literature review of various flood conditioning factors. Based on the literature review and with the help of experts (Delphi Method) certain flood conditioning factors are identified. In the third section the proposed approach is discussed and also impeccable evaluation of ISM based factor identification is done. This section includes modeling of flood causing factors to obtain a directed graph which establish a relationship among the flood causing factors. 
In this paper, total eleven factors are identified using which an ISM model is developed. Then the fourth section is concluding section that is drawn from the literature review and the proposed approach followed by future scope. Finally references are placed at last.

\section{LITERATURE REVIEW}

Flood disasters are considered to be the most devastating natural hazards. Flood risk management by assessing the effects is a great challenge faced by the world today [24]. There are many researches going on which are trying to find out methods to mitigate the effects of flood. Though Flood is a natural disaster but there are many factors which causes floods [12]. There are enormous parameters that can be considered such as Slope of an area, Aspect Ratio, Altitude, heavy rainfall, prolonged rainfall, snow melt, coastal flood,

sudden water release, volcanic eruptions, deforestation, change in land use, catastrophic failure, population pressure, poor water management, river management, improper dam construction, sudden climate change, global warming and many more. But by conducting extensive literature survey we have considered some of the influential parameters. These parameters are shown in Table 1.

Table 1. List of Identified Factors

\begin{tabular}{|l|l|l|}
\hline No. & Brief risk description & Id. \\
\hline 1 & Slope Angle & F1 \\
\hline 2 & Aspect & F2 \\
\hline 3 & Altitude & F3 \\
\hline 4 & Curvature & F4 \\
\hline 5 & Rainfall & F5 \\
\hline 6 & SPI & F6 \\
\hline 7 & TWI & F7 \\
\hline 8 & River Density & F8 \\
\hline 9 & Distance to river & F9 \\
\hline 10 & Lithology & F10 \\
\hline 11 & Land use & F11 \\
\hline
\end{tabular}

Ref. [6] mentions that The Center for Research on the Epidemiology of Disasters (CRED) defines a flood as "a noticeable rise of water level in a river, lake, reservoir or coastal region". There are various interrelated and multifaceted events and factors that cause floods. Natural factors include heavy or prolonged rainfall, snowmelts, or storm surges from cyclones etc. whereas some of the human factors include catastrophic failures, alteration land use change and inadequate drainage systems. The Geographic regions such as coastal areas, drainage basins and lake shores are intensely at risk from heavy winds and storms. Environmental and physical land features such as soil type, the presence of vegetation, and other drainage basin properties also influence floods.

The aim of the review was to illustrate the causes and the impact of floods on the human population and to identify various associated risk factors. There are various other causes such as TWI, SPI, Litho logy, and Distance to river etc.

Ref [15] says that the heavy rainfall and synchronization of overflow of the important rivers are generally considered to be the significant factor causing floods. Some of the factors which also should be seriously considered as major contributors to the recent floods are change in the base level of the rivers which is due to rising and sinking of the local sea level and unwanted sludge accumulation on flood plains.

Ref [16] in their paper have focused on Mumbai which is the capital city of the Maharashtra. Mumbai being a low lying and tureen area gets flooded almost every year during rainy seasons and high tides. In this paper they have tried to figure out certain causes of floods and there forth introduce new methods that can reduce the floods and the impact caused by them. Certain reasons for floods in Mumbai are stated as follows: Heavy Rains and Rising Sea Levels, Extensive Reclamation and Faulty Zoning Regulations, Faltering Drainage Systems, Mumbaie's Natural Drain, Incapable Storm Water Drains, Reduction in the drainage basin of Mithi river, Bandra -Worli sea link, Path of the Mithi River being changed due to CSIA "es runway.

Ref [4] discussed flood risk in Malaysia, which has increased substantially in recent years to an extent due to change in the physical attributes of the hydrological system. These changes are the result of various human activities such as continuous development going on in already densely populated flood plains, invasion on areas that are subject to flood, deforestation and hill slopes development.

Ref [10] in his paper calculated a composite flood hazard index (FHI) by applying AHP to get relative impact weight of flood causing factors. The causative factors in the study taken are overflow soil type, the kind of surface slope, surface roughness, drainage density, distance to main water channel and the type of land use.

Ref [1] analyzed various causes of flood occurrence in recent years in Kedah, a northern state in Malaysia. This paper states that finding causes, both direct and indirect will be essential to find better solution. Analytical Hierarchy Process (AHP) method is used in which pair wise questionnaire is developed and distributed to selected respondents. Results show that human factors are recognized to be more critical than natural causes. There by the identified causes can be overcome causing reduction in flood disasters.

Generino Fernandez uses Analytical Hierarchy Process (AHP) method along with Geographic Information System (GIS) for flood risk analysis and evaluation. Certain flood risk factors with their weight values were identified and results were validated. The factors were analyzed using GIS and thus can be used to promote appropriate land use policy thus can minimize threat to lives during floods.

By using hydro-morphological parameters, multi criteria analysis technique were tested and evaluated for flood risk assessment purpose [9]. 
The multi criteria analysis technique was used to analyze the parameters having different effects on the floods generated.

Ref [21] in this paper constructs a vulnerability index by using a vulnerability framework. The high vulnerability scores, high vulnerability hazards and high flood exposure zones were highlighted to determine the population at risk.

The analysis includes socioeconomic and spatial data to illustrate the population which are more vulnerable to floods with change in climate.

Ref. [2] Presented Multi Criteria Analysis (MCA) and geographical information system (GIS) tool based assessment of flood vulnerability. Certain flood causing natural factors were identified such as type of soil, rainfall, land usage and basin size and slope. Once the effective flood causing factors were identified, several approaches to MCA in a GIS environment were applied. There are several studies in flood risk assessment that uses Multicriteria analysis (MCA) methods. Some of them include GIS- based multicriteria evaluation in Turkey [31] and in Kenya Ouma [20] [30] assessed flood vulnerability in a river basin in Nigeria, [27] uses GIS and satellite imagery for flood risk assessment in Thailand, [18][19] applied GIS based multicriteria for assessing flood in Greece.

Ref .[29] Uses MCA and GIS techniques to assess flood prone areas by taking into account the adverse effect of the process of urbanization posing threat of flooding. The land use change that takes place because of urbanization is also taken into account to observe the temporal change of regional flood hazard.

\section{PROPOSED APPROACH \& IMPECCABLE EVALUATION}

The proposed approach uses Interpretive Structural Modeling (ISM) to model and measure the flood conditioning factors. It explores the dynamic influence of various factors by considering dependent and independent variables or elements [22][28]. Further MICMAC analysis is applied which helps in classification of variables into different classes.

This research encompasses identification of contextual relationship [5] between 11 flood causing risk factors. Further structural self-interaction matrix (SSIM) [25] was created. Then the SSIM is converted into Initial reach ability matrix. We then examine transitivity and then convert it into final reach ability matrix, followed by development of a graphical model named as digraph for ISM. Finally based on the relative Driving Powers and Dependence powers of factors with respect to each other MICMAC analysis is performed. These steps have been elaborated in Table 2 .

Table 2. Steps Used In Proposed Approach

\begin{tabular}{|l|}
\hline Step 1: Flood Conditioning Factors are Identified \\
\hline \hline Step 2: A Conceptual Relationship is Established. \\
\hline \hline Step 3: A Structural Self Interaction matrix (SSIM) is \\
developed. \\
\hline \hline $\begin{array}{l}\text { Step 4: Transitivity is Explored and Final Rechability } \\
\text { Matrix is Achieved. }\end{array}$ \\
\hline \hline $\begin{array}{l}\text { Step 5: Partition Final Rechability Matrix into Different } \\
\text { Levels. }\end{array}$ \\
\hline \hline $\begin{array}{l}\text { Step 6: Directed Graph is Drawn and Converted into } \\
\text { ISM. }\end{array}$ \\
\hline \hline Step 7: MICMAC analysis is performed. \\
\hline
\end{tabular}

Step 1: Firstly identify the relevant factor. For this research, some factors that are influential in causing flood are identified (shown is Table 1.) based on literature survey and experts opinion from relevant field.

Step 2: Based on factors identified in step1, a conceptual relationship is established between the factors. Further the influence relationship is considered for the research.

Step 3: In this step a Structural Self Interaction matrix (SSIM) is developed shown in Figure 1. All the diagonal values are marked as 1 . The symbols used to denote the direction of relationship are as follows:

1. If factor $\mathrm{i}$ influence factor $\mathrm{j}$ it is termed as " $\mathrm{V}$ "

2. If factor $\mathrm{j}$ influence factor $\mathrm{I}$ it is termed as " $\mathrm{A}$ ".

3. If factor $\mathrm{i}$ and $\mathrm{j}$ influence each other it is termed as " $\mathrm{X}$ ".

4. If factor $\mathrm{i}$ and $\mathrm{j}$ are not related it is termed as " $\mathrm{O}$ ".

\begin{tabular}{|c|c|c|c|c|c|c|c|c|c|c|c|}
\hline & $\mathrm{F} 1$ & $\mathrm{~F} 2$ & $\mathrm{~F} 3$ & $\mathrm{~F} 4$ & $\mathrm{~F} 5$ & $\mathrm{~F} 6$ & $\mathrm{~F} 7$ & $\mathrm{~F} 8$ & $\mathrm{~F} 9$ & $\mathrm{~F} 10$ & $\mathrm{~F} 11$ \\
\hline F1 & 1 & $\mathrm{X}$ & $\mathrm{X}$ & $\mathrm{X}$ & $\mathrm{O}$ & $\mathrm{V}$ & $\mathrm{V}$ & $\mathrm{O}$ & $\mathrm{O}$ & $\mathrm{O}$ & $\mathrm{V}$ \\
\hline F2 & & 1 & $\mathrm{O}$ & $\mathrm{O}$ & $\mathrm{O}$ & $\mathrm{V}$ & $\mathrm{V}$ & $\mathrm{O}$ & $\mathrm{O}$ & $\mathrm{O}$ & $\mathrm{V}$ \\
\hline F3 & & & 1 & $\mathrm{O}$ & $\mathrm{V}$ & $\mathrm{V}$ & $\mathrm{V}$ & $\mathrm{O}$ & $\mathrm{O}$ & $\mathrm{O}$ & $\mathrm{V}$ \\
\hline F4 & & & & 1 & $\mathrm{O}$ & $\mathrm{V}$ & $\mathrm{V}$ & $\mathrm{O}$ & $\mathrm{O}$ & $\mathrm{O}$ & $\mathrm{V}$ \\
\hline F5 & & & & & 1 & $\mathrm{~V}$ & $\mathrm{~V}$ & $\mathrm{~V}$ & $\mathrm{~V}$ & $\mathrm{~V}$ & $\mathrm{X}$ \\
\hline F6 & & & & & & 1 & $\mathrm{X}$ & $\mathrm{A}$ & $\mathrm{O}$ & $\mathrm{O}$ & $\mathrm{O}$ \\
\hline F7 & & & & & & & 1 & $\mathrm{~V}$ & $\mathrm{O}$ & $\mathrm{O}$ & $\mathrm{O}$ \\
\hline F8 & & & & & & & & 1 & $\mathrm{O}$ & $\mathrm{O}$ & $\mathrm{V}$ \\
\hline F9 & & & & & & & & & 1 & $\mathrm{O}$ & $\mathrm{V}$ \\
\hline F10 & & & & & & & & & & 1 & $\mathrm{~V}$ \\
\hline F11 & & & & & & & & & & & 1 \\
\hline
\end{tabular}

Figure 1. Structural Self Interaction matrix

Step 4: In this step each cell of SSIM is replaced either by 1 or 0 to develop initial reachability matrix in binary form (shown in Figure 3.). If factor 1 influence factor 2 or vice versa mark it as 1 otherwise mark it as 0 . After this Transitivity is explored and final rechability matrix is achieved. That is, factor 1 influence factor 2 and factor 2 influence factor 3 , then factor 1 also influence factor 3 . The cells in initial reachability matrix having transitivity are marked as $1 *$. Figure 3 . shows the final reachability matrix for the 11 identified factors. 


\begin{tabular}{|r|r|r|r|r|r|r|r|r|r|r|r|}
\hline & F1 & F2 & F3 & F4 & F5 & F6 & F7 & F8 & F9 & F10 & F11 \\
\hline F1 & 1 & 1 & 1 & 1 & 0 & 1 & 1 & 0 & 0 & 0 & 1 \\
\hline F2 & 1 & 1 & 0 & 0 & 0 & 1 & 1 & 0 & 0 & 0 & 1 \\
\hline F3 & 1 & 0 & 1 & 0 & 1 & 1 & 1 & 0 & 0 & 0 & 1 \\
\hline F4 & 1 & 0 & 0 & 1 & 0 & 1 & 1 & 0 & 0 & 0 & 1 \\
\hline F5 & 0 & 0 & 0 & 0 & 1 & 1 & 1 & 1 & 1 & 1 & 1 \\
\hline F6 & 0 & 0 & 0 & 0 & 0 & 1 & 1 & 0 & 0 & 0 & 0 \\
\hline F7 & 0 & 0 & 0 & 0 & 0 & 1 & 1 & 1 & 0 & 0 & 0 \\
\hline F8 & 0 & 0 & 0 & 0 & 0 & 1 & 0 & 1 & 0 & 0 & 1 \\
\hline F9 & 0 & 0 & 0 & 0 & 0 & 0 & 0 & 0 & 1 & 0 & 1 \\
\hline F10 & 0 & 0 & 0 & 0 & 0 & 0 & 0 & 0 & 0 & 1 & 1 \\
\hline F11 & 0 & 0 & 0 & 0 & 1 & 0 & 0 & 0 & 0 & 0 & 1 \\
\hline
\end{tabular}

Figure2.Reachability matrix

Following is the conversion of Structural Self Interaction Matrix (SSIM (I,J)th entry) into Rechability Matrix:

1. $\mathrm{V} \Rightarrow \operatorname{SSIM}(\mathrm{I}, \mathrm{J})=1$ and $\operatorname{SSIM}(\mathrm{J}, \mathrm{I})=0$

2. $\mathrm{A} \Rightarrow \operatorname{SSIM}(\mathrm{I}, \mathrm{J})=0$ and $\operatorname{SSIM}(\mathrm{J}, \mathrm{I})=1$

3. $X \Rightarrow \operatorname{SSIM}(\mathrm{I}, \mathrm{J})=1$ and $\operatorname{SSIM}(\mathrm{J}, \mathrm{I})=1$

4. $\mathrm{O}=>\operatorname{SSIM}(\mathrm{I}, \mathrm{J})=0$ and $\operatorname{SSIM}(\mathrm{J}, \mathrm{I})=0$

\begin{tabular}{|c|c|c|c|c|c|c|c|c|c|c|c|}
\hline & F1 & F2 & F3 & F4 & F5 & F6 & F7 & F8 & F9 & F10 & F11 \\
\hline F1 & 1 & 1 & 1 & 1 & $1^{*}$ & 1 & 1 & $1^{*}$ & 0 & 0 & 1 \\
\hline F2 & 1 & 1 & 0 & 0 & 0 & 1 & 1 & $1^{*}$ & 0 & 0 & 1 \\
\hline F3 & 1 & $1^{*}$ & 1 & 0 & 1 & 1 & 1 & $1^{*}$ & $1^{*}$ & 0 & 1 \\
\hline F4 & 1 & $1^{*}$ & $1^{*}$ & 1 & $1^{*}$ & 1 & 1 & $1^{*}$ & $1^{*}$ & 0 & 1 \\
\hline F5 & 0 & 0 & 0 & 0 & 1 & 1 & 1 & 1 & 1 & 1 & 1 \\
\hline F6 & 0 & 0 & 0 & 0 & 0 & 1 & 1 & $1^{*}$ & 0 & 0 & 0 \\
\hline F7 & 0 & 0 & 0 & 0 & 0 & 1 & 1 & 1 & 0 & 0 & 0 \\
\hline F8 & 0 & 0 & 0 & 0 & 0 & 1 & $1^{*}$ & 1 & 0 & 0 & 1 \\
\hline F9 & 0 & 0 & 0 & 0 & $1^{*}$ & 0 & 0 & 0 & 1 & 0 & 1 \\
\hline F10 & 0 & 0 & 0 & 0 & $1^{*}$ & 0 & 0 & 0 & 0 & 1 & 1 \\
\hline F11 & 0 & 0 & 0 & 0 & 1 & 0 & 0 & 0 & 0 & 0 & 1 \\
\hline
\end{tabular}

Figure 3. Final Reachability Matrix

Step 5: Once the final reach ability matrix is formed, conical matrix is derived (Figure 4.). Then the driver power and dependence power is calculated. Driver power is calculated by counting the number of ones in rows while the dependence power is calculated by counting the number on ones in the column. Further driver and dependence ranks are assigned. The factor with the maximum driver value is ranked as I and that with the lower values are given corresponding ranks. Similarly the ranks are allocated to the dependence factors.

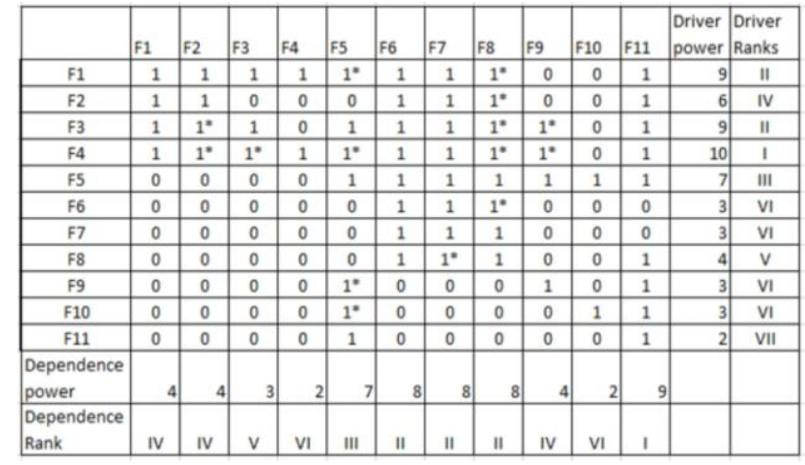

Figure 4. Conical Matrix

Then partition final reach ability matrix into different levels through repetitive iterations (shown in Figure 5.).

\begin{tabular}{|l|l|l|l|l|l|}
\hline Level 4 & F4 & F1 & & & \\
\hline Level 3 & F3 & & & & \\
\hline Level 2 & F2 & F5 & F8 & F9 & F10 \\
\hline Level 1 & F6 & F7 & F11 & & \\
\hline
\end{tabular}

Figure 5. Identified Levels

Step 6: With the help of conical matrix formed in step 5 a directed graph is drawn (Figure 6.) showing the relationship between various factors. A directed graph also known as digraph is a graphical representation in which nodes are arranged according to their levels and directed links are drawn between them to show the relationship among the nodes. Each

node is now replaced with the corresponding factors to form ISM.

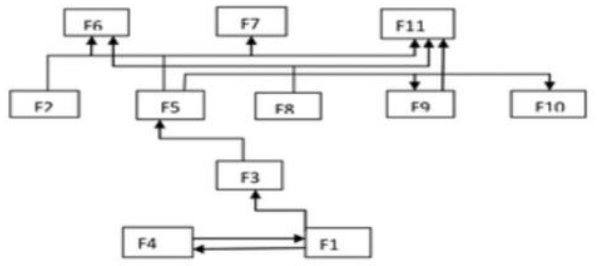

Figure 6. Diagraph

Step 7: Finally after ISM is build, MICMAC analysis is done. MICMAC analysis is mainly used for the analysis of driving and dependence powers of the factors under consideration. Based on the driving power and dependence power identified in conical matrix the factors are divided into four groups (Figure 7.) mentioned below:

1. Autonomous Parameters: These are the parameters having weak driver power and weak dependence power. That means the factors which are grouped in this category do not have much influence on the system.

2. Dependent Parameters: The parameters belong to this category have weak driver power but strong dependence power. That means the factors under this category will be strongly dependent on other parameters.

3. Linkage Parameters: These are the parameters having strong driver power as well as strong dependence power. That means the factors are strongly related with other factors.

4. Independent Parameters: These parameters have weak dependence power but a strong driver power. That is these factors are independent factors as they drive other factors and are least dependent over other factors. 


\begin{tabular}{|c|c|c|c|c|c|c|c|c|c|c|c|}
\hline \multicolumn{12}{|c|}{11} \\
\hline 10 & & 54 & & & & & & & & & \\
\hline 9 & & & F3 & $\mathrm{F} 1$, & & & & & & & \\
\hline 8 & & IV & \multicolumn{3}{|c|}{ Independent Parameters } & & IIII & & \multicolumn{3}{|c|}{ Linkage Parameters } \\
\hline 7 & & & & & & \multicolumn{2}{|r|}{ F5 } & & & & \\
\hline 6 & & & & $F 2$ & & & & & & & \\
\hline 5 & & & & & & & & & & & \\
\hline 4 & & 1 & Autonor & mous $\mathrm{Pa}$ & neters & & $\|$ & F8 & Depend & ce Par & meters \\
\hline 3 & & F10 & & $\mathrm{Fg}$ & & & & $F 6,77$ & & & \\
\hline 2 & & & & & & & & & F11 & & \\
\hline 1 & & & & & & & & & & & \\
\hline & 1 & 2 & 3 & 4 & 5 & 6 & 7 & 8 & 9 & 10 & 11 \\
\hline
\end{tabular}

DEPENDENCE POWER

Figure 7. MICMAC Analysis

The above grouping is analogous to that done by [26] Similar to conical matrix which shows the driving power and dependence power of each parameter, we obtained these powers for each of the factors. By using the values of driver power and dependence power, a diagram is prepared as shown in Figure 7.

This diagram is divided into four quadrants namely "autonomous parameters", "dependent parameters", "linkage parameters" and "independent parameters". Based on the conical matrix, we place the factor in one of the quadrant. All the parameters are placed in quadrants according to their driving and dependence power.

In this present research study, the interrelationships and dependencies between various factors responsible for flood conditioning were identified. The data was gathered with the help of experts (Delphi method) and extensive literature survey done. Interpretive Structural Modeling (ISM) was applied to model relationship among the factors. Thereafter MICMAC analysis is applied to group the factors into different levels. Out of 11 considered factors five factors were grouped as Autonomous. This shows that most of the factors taken do not have a significant effect on other factors. One factor was found to be dependence parameter. Four factors are independent factors having no dependence. From the factors considered only one of the factors was grouped in linkage parameters. The present research not only ascertains the hidden inter relationships among considered factors but it also specifies the dominant factor having greater driving power through their hierarchical dependence. This relationship would indeed be helpful in finding better flood risk reduction solutions. The most important driver powers factors can be concentrated more and can be given more weight age while designing risk reduction strategies. Thus many drastic losses can be averted.

As a future scope of this work more factors can be added to it as there are many other flood conditioning factors. Moreover this technique can also be implemented on multiple risk factors there by finding relationship among them. Also as an improvement to the current work we could even use ISM and fuzzy MICMAC technique [8]. Fuzzy logic deals with imprecision and the data available regarding

\section{CONCLUSION AND FUTURE SCOPE}

floods and similar other natural disasters are imprecise in nature. Thus by using fuzzy logic the precision level of the research can be increased. Thus the performance of the above technology can be increased.

\section{REFERENCES}

1. N.I.R.A. Azis and H. Lamsali, "Prioritizing Critical Factors of Floods In Kedah Using Pairwise Comparison Approach", In Proceedings of Symposium on Technology Management \& Logistics (STML-Go Green), 2016.

2. S.M. Blistanova, M. Zelenakova, P. Blistan and V. Ferencz, "Assessment of flood vulnerability in Bodva river basin", Acta Montanistica Slovaca, 21, 2016,19-28.

3. M. M. D. Brito, and M. Evers, "Multi-criteria decision-making for flood risk management: a survey of the current state of the art". Natural Hazards and Earth System Sciences, 16, 2016, 1019-1033.

4. N.W. Chan, "Increasing flood risk in Malaysia: causes and solutions", Disaster Prevention and Management An International Journal, 6(2), 1997, 72-86.

5. A. Diabat, K. Govindan, and V. Panicker, "Supply Chain Risk Management and Its Mitigation In A Food Industry", International Journal of Production Research, 50, 2012, 3039-3050.

6. S. Doocy, A. Daniels, S. Murray, T.D. Kirsch, "The Human Impact of Floods: a Historical Review of Events 1980-2009 and Systematic literature Review". PLOS Currents Disasters.

7. J.H. Danumah, S.N. Odai, B.M. Saley, J. Szarzynski, M. Thiel, A Kwaku, F.K. Kouame, F.K. and L.Y. Akpa, "Flood risk assessment and mapping in Abidjan district using multi-criteria analysis (AHP) model and geoinformation techniques", (cote d'ivoire). Geoenvironmental Disasters, 2016.

8. D.K Dewangan, R. Agrawal, and V. Sharma, "Enablers for Competitiveness of Indian Manufacturing Sector: An ISM-Fuzzy MICMAC Analysis". Procedia - Social and Behavioral Sciences, 189, 2016, $416-432$.

9. A.M Elmoustafa, "Weighted Normalized Risk Factor For Floods Risk Assessment". Ain Shams Engineering Journal, 3(4), 2012, 327-332.

10. I. Elkhrachy, "Flash Flood Hazard Mapping Using Satellite Images and GIS Tools: A case study of Najran City, Kingdom of Saudi Arabia (KSA)". The Egyptian Journal of Remote Sensing and Space Sciences, 18, 2015,261-278.

11. K. Govindan and A.N. Haq, "Analysis of interactions of criteria and sub-criteria for the selection of supplier in the built-in-order supply chain environment". International Journal of Production Research, 45 (17), 2007, 3831-3852.

12. Y. Hundecha, J. Parajka and A. Viglione, (2017). "Flood type classification and assessment of their past changes across Europe". Hydrology and Earth System Sciences, ,2017, 365.

13. A.N.A Jawad and H. Bashir, "Hierarchical structuring of organizational performance using interpretive structural modeling", Industrial Engineering and Operations Management, 2015.

14. P. Jain, A. Sharma and L. Ahuja, "ISM Based Identification of Quality Attributes for Agile Development". In Proceedings of the 5th International Conference on Reliability, Infocom Technologies and Optimization (Trends and Future Directions) (ICRITO), 2016, pp. 615-61, Noida, India.

15. M. Khalequzzaman, "Recent Floods in Bangladesh: Possible Causes and Solutions", Natural Hazards, 9(1-2), 1994,65-80.

16. P.T. Kadave, A.D. Kale, S. Narwade, "Mumbai Floods, Reasons and Solutions", International Journal of Scientific and Research Publications, 6(3), 2016,2250-3153.

17. S. Nagpal, A. Kumar, S.K. Khatri, "Modeling interrelationships between CSF in ERP implementations: total ISM and MICMAC approach". International Journal of System Assurance Engineering and Management, 8(4), 2017,782-798.

18. G. Kandilioti and C. Makropoulos, "Preliminary flood risk assessment The case of Athens". Natural Hazards, 61 (2), 2012, 441-468.

19. K. Kazakis, I. Kougias and T. Patsialis, "Assessment of flood hazard areas at a regional scale using an index based approach and Analytical Hierarchy Process: Application in Rhodope -Evros region”, Greece. Science of the Total Environment, 538, 2015, 555-563

20. Y.O. Ouma and R. Tateishi, "Urban Flood Vulnerability and Risk Mapping Using Integrated Multi-Parametric AHP and GIS Methodological Overview and Case Study Assessment". Water, 6(6), 2014, 1515-1545.
Exploring $E$

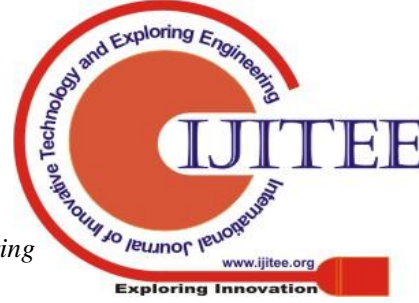


21. R.J Rasch, "Assessing urban vulnerability to flood hazard in Brazilian municipalities. Environment \& Urbanization", 2016, 28(1).

22. L. Shen, X. Song, Y. Wu, S. Liao, and X. Zhang, "Interpretive Structural Modeling based factor analysis on the implementation of Emission Trading System in the Chinese building sector". Journal of Cleaner Production, 2016, 127.

23. G.P. Siddayao, S.E. Valdez and P.L. Fernandez, "Analytic Hierarchy Process (AHP) in Spatial Modeling for Floodplain Risk Assessment". International Journal of Machine Learning and Computing, 4, 2014.

24. S. Sharma, and V. Sharma, "A Review on Using Soft Computing Techniques In Disaster Management and Risk Assessment". In Proceedings of International Conference on Innovation and Challenges in Cyber Security (ICICCS-INBUSH), 2016, pp. 119-122. Noida, India.

25. N. Sohani and N. Sohani, "Developing Interpretive Structural Model for Quality Framework in Higher Education: Indian Context". Journal of Engineering, Science \& Management Education, 5, 2012, 495-501.

26. N. Sachdeva, O. Singh, and P.K. Kapur, "Modeling Critical Success Factors for Adoption of Big Data Analytics Project: An ISM-MICMAC Based Analysis", Communications In Dependability And Quality Management, An International Journal, 18, 4, 2015, 93-110.

27. C.H. Tanavud, C.H. Yongchalermchai, A. Bennui, O. Densreeserekul, "Assessment of flood risk in Hat Yai Municipality, Southern Thailand, using GIS”. Journal of Natural Disaster Science, 26 (1), 2014, 1-14

28. C. Valmohammadi, S. Dashti, "Using interpretive structural modeling and fuzzy analytical process to identify and prioritize the interactive barriers of e-commerce implementation". Information \& Management, $53(2), 2016$.

29. Y. Xiao, S. Yi and Z. Tang, "GIS-based multi-criteria analysis method for flood risk assessment under urbanization", In Proceedings of 24th International Conference on Geoinformatics, Galway, Ireland , 2016, pp. 1-5.

30. S. Yahaya, N. Ahmad, N. and F.R. Abdalla, "Multicriteria Analysis for flood vulnerable areas in Hadejia-Jama'are river basin, Nigeria". European Journal of Scientific Research, 42 (1), ,2010, 71-83.

31. G. Yalcin and Z. Akyurek, "Analysing flood vulnerable areas with multicriteria evaluation", In Proceedings from XXth ISPRS Congress of Geo-Imagery Bridging Continents, 2014, pp. 359-364.

\section{AUTHORS PROFILE}

Swati Sharma received her Bachelor's and Master's degree in Computer science and engineering in 2005 and 2012 respectively. Currently working as Assistant Professor In CSE department in KIET Group of Institutions, Ghaziabad, India. She is currently a $\mathrm{PhD}$ student in AKTU, India. Her research interest is in field of Applicative soft computing..

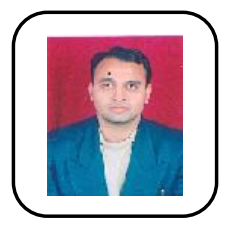

Dr. Vineet Sharma received his Master's degree in I.T. from AAIDU, India and $\mathrm{PhD}$ degree from Jamia Milia Islamia , New Delhi, India. Currently working as Professor and Head of Department in department of CSE in KIET group of Institutions .His research interest is in the field of computer networks and soft computing. 